\title{
Application of smart phone agro-advisory services of m4agriNEI in climate smart natural resource management in agriculture by tribal farmers of Meghalaya: an empirical study with structural equation modeling
}

\section{RJ Singh, Ram Singh, NJ Singh, TS Anurag \& Bai Koyu}

Journal of Agriculture and Ecology

\section{Journal of}

ISSN: 2456-9410

Volume: 9

Journal of Agriculture and Ecology (2020) 9: 67-77 http://doi.org/10.53911/JAE.2020.9108

\section{Agriculture and}




\title{
Application of smart phone agro-advisory services of m4agriNEI in climate smart natural resource management in agriculture by tribal farmers of Meghalaya: an empirical study with structural equation modeling
}

\author{
RJ Singh ${ }^{1} \not$, Ram Singh ${ }^{1}$, NJ Singh ${ }^{1}$, TS Anurag ${ }^{2} \&$ Bai Koyu ${ }^{1}$ \\ ${ }^{1}$ College of P.G. Studies in Agricultural Sciences of CAU, Imphal at Umiam, Meghalaya \\ ${ }^{2}$ Principal Research Scientist, Digital India Corporation, Ministry of Electronics \& IT, New Delhi, India \\ $\nabla$ Corresponding author: RJ Singh, josndri@gmail.com
}

\section{Article Info}

Article history

Received: 10 July 2020

Accepted: 25 July 2020

Available online: 30 July 2020

Key Words: AAS, ICT, m4agriNEI, ClimateSmart Natural Resource Management, Structural Equation Modeling.

\section{Abstract}

Smart phone applications are increasingly being used by farmers of North East India to help them make informed decision on Climate-Smart Natural Resource Management (CSNRM). The research project m4agriNEI is an innovative mix of Smart Phone and web applications along with Toll Free IVRS based farmer specific agro-advisory system being implemented at College of P.G. Studies in Agricultural Sciences of CAU, Imphal at Umiam, Meghalaya in collaboration with Digital India Corporation, New Delhi. The present study aims to investigate and confirm a successful model application of smart phone Agro-Advisory Services (AAS) by the registered farmers of m4agriNEI by incorporating five constructs through Structural Equation Modelling on CSNRM in Agriculture. Survey research design was followed in the study by incorporating exploratory and confirmatory factor analysis. A total of 363 registered farmers were treated as respondents in the study. The study unveiled that 'Smart Phone Agro-Advisory Services Acceptance Model' of m4agriNEI is a successful model on empowering the tribal farmer of Meghalaya in climate smart natural resource management in agriculture by providing right information in right time through a smart phone based agro-advisory system.

Copyright (C2020 Singh et al., This is an open access article published under the terms of the Creative Commons Attribution License, which permits unrestricted use, distribution, and reproduction in any medium, provided the original work is properly cited.

Preferred citation: Singh RJ, Singh R, Singh NJ, Anurag TS \& Koyu B. 2020. Application of smart phone agro-advisory services of m4agriNEI in climate smart natural resource management in agriculture by tribal farmers of Meghalaya: an empirical study with structural equation modeling. Journal of Agriculture and Ecology, 9: 67-77; http://doi.org/10.53911/JAE.2020.9108.

\section{Introduction}

Information and communication have always mattered in agriculture. Updated information allows farmers to cope with and even benefit from many farming opportunities. Providing such knowledge can be challenging, however, because the highly localized nature of agriculture means that information must be tailored specifically to distinct conditions. The agriculture of hill state, Meghalaya is facing new and severe challenges in its own right. The region, by and large is characterized by fragility, marginality, inaccessibility, cultural heterogeneity, diverse ethnicity and rich biodiversity. In this juncture, with rising food prices that have 
pushed over 80 per cent of the total population who are predominantly farmers, more effective interventions are essential in agriculture (GoM 2016). Given these challenges, the application of ICT in agriculture is well timed. To cope, tribal farmers need useful and reliable information at the right time. Such information assists them in making complex decisions, which then impact the livelihoods of their families and the broader society. Improving farmers' prompt access to that information is paramount to reducing poverty and feeding more people. The tremendous increase in the use of information and communications technology, especially among rural communities, has opened up innovative ways in delivering agricultural advisories and other information services aimed at increasing rural livelihoods. Smart Phone-based information delivery services to agrarian communities, and experimentation with this channel is heavily increasing. The massive numbers of people with access to Smart Phones, many of them at the bottom of the economic pyramid in the state, makes this potentially an extremely effective medium for delivering information services.

\section{Smart phone based agro-advisory system in north-east India (m4agriNEI)}

The m4agriNEI is an innovative mix of smart phone and web applications along with toll free IVRS based farmer specific advisory system. There is a smart phone interface at the front end for the farmers and web interface at the back end for the agricultural experts. The system allows transmitting the data through voice, text and images from both end (farmer to expert and back). Also, the farmer can call the system to get any information as well as to get the AAS. This system provides the options to the farmer to subscribe for the various information services. Farmer will receive information (SMS/voice call/picture/video clippings) for only those services for which farmer have subscribed and have an option at a later date to either select some more services or unsubscribe to some of the existing services. The experts at back end (m4agriNEI laboratory with domain expert and virtual experts) can access to the database of the farmers while responding the farmer's queries. Further, designated farmer coordinators and rural youth facilitate the registered farmers in getting farm information and knowledge and also, they provide feedback to the m4agriNEI system. The system is connected to a centralized database, which have information on farmer, farm history and previous interactions. The project - m4agriNEI has been taken up by the Media Lab Asia a section 25 company setup by the Department of Electronics \& Information Technology, MeitY, GoI along with the Central Agricultural University, Imphal. The College of Post-Graduate Studies in Agricultural Sciences, Umiam, Meghalaya is the prime agency for the implementation of the pilot project in Meghalaya. The project was launched in June, 2012 and is still being successfully implemented till date.

New technologies provide new opportunities; adoption and acceptance of these new promising technologies have become a significant problem for both farmers and scientists. Hence, it is an important issue to understand which factors contribute to 
users' intentions to use new Smart Phone based AAS of m4agriNEI. The basic challenge is to understand how and why people adopt or do not adopt Smart Phone services. Sarker and Wells (2003) claimed that there is not a clear understanding of the motivations and circumstances, which guide consumers to adopt and use Smart Phone devices. In most cases, the successful diffusion of new Smart Phone service is partially determined by willingness of users to adopt these services (Gao et al. 2011). While there are some other factors like reference prices of the services offered, standards, infrastructure and content (Barnes 2002), compatibility, individual mobility and subjective norms (Schierz et al. 2010), which seem to be affecting more to the users' intentions. Researchers are forced to investigate the determinants of user acceptance, because of enhancing applications, continuous emergence of new services and devices, existing competition, and inevitable developments in technology. Only a few studies addressed the acceptance of Smart Phone services, while there has been a great deal of research on Smart Phone services development and Smart Phone and wireless networks. Few studies have investigated the potential factors affecting the user adoption of Smart Phone services. In this context, Gao et al. (2008) offered a new Smart Phone services acceptance model by using existing technology acceptance framework by integrating new theoretical constructs.

\section{Theoretical framework and hypotheses}

This research work studies on acceptance of smart phone AAS by farmers on climate smart natural resource management in agriculture by providing right information in right time through a smart phone based agroadvisory system. The study adapts 'Smart Phone Service Acceptance Model' which was originally proposed by Gao et al. (2008) and a research model called 'Smart Phone AgroAdvisory Services Acceptance Model on Climate Smart Natural Resource Management' as depicted in Figure 1 is propounded by integrating five constructs viz., 1. Context on Climate Smart Natural Resource Management (C), 2. Trust on Climate Smart Natural Resource Management (T), 3. Perceived Usefulness on Climate Smart Natural Resource Management (PU), 4. Perceived Ease of Use on Climate Smart Natural Resource Management (PEU), and 5. Intention to Accept on Climate Smart Natural Resource Management (IA).

This discourse poised a research question on what are the concrete factors influencing the adoption of smart phone AAS by tribal farmers of Meghalaya on Climate Smart Natural Resource Management. Therefore, the specific objective of the study is to investigate and confirm the model of acceptance and adoption of Smart Phone AAS by the registered farmers of m4agriNEI with the following hypotheses with respect to the constructs of the study.

The 'Context on Climate Smart Natural Resource Management' is defined as any personal and agricultural information that may influence the farmer on Climate Smart Natural Resource Management when he is using smart phone internet. Mallat et al. (2009) assumed that the use of context is an essential factor in affecting user acceptance of smart phone systems. 


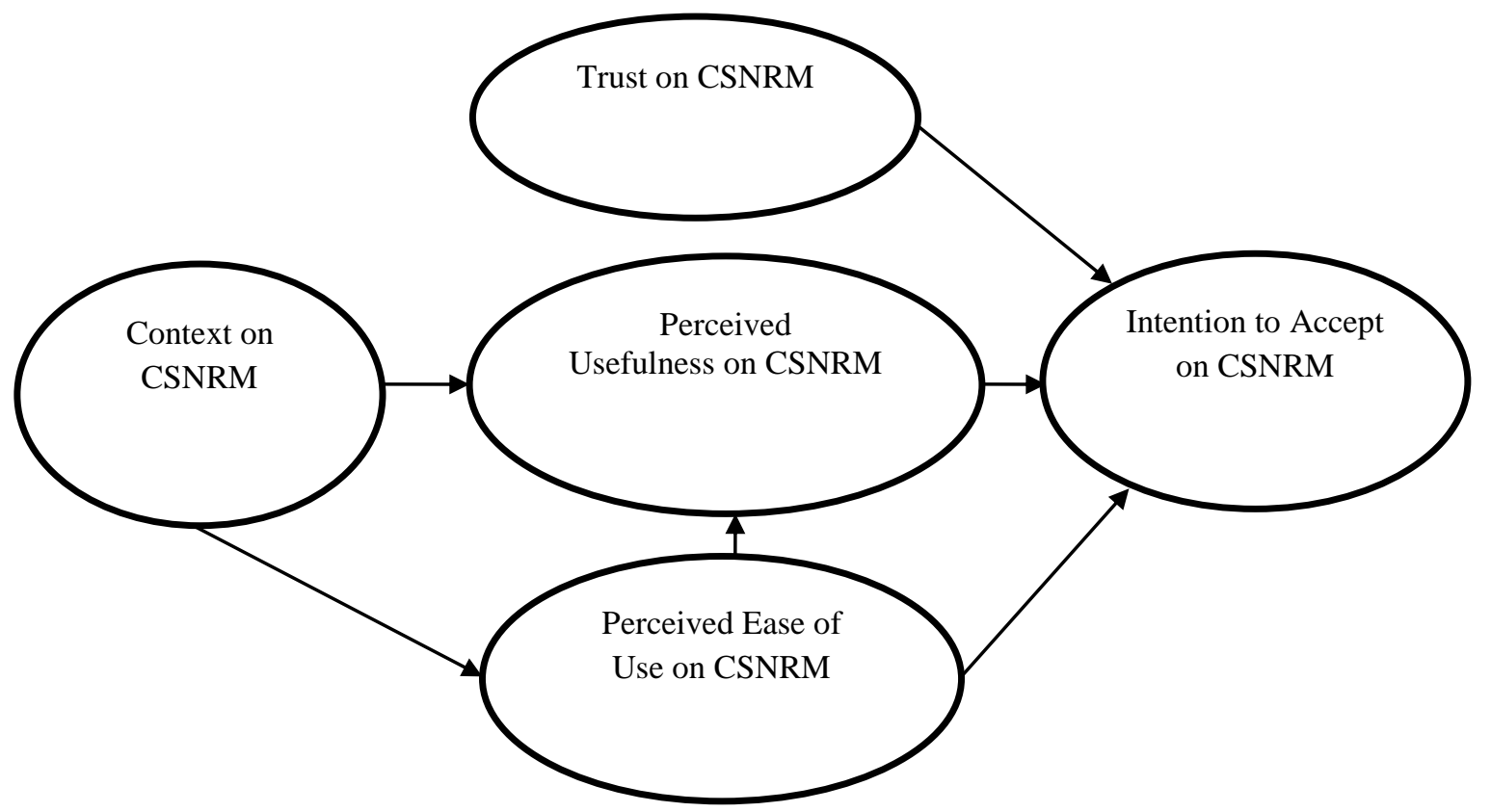

Figure 1. Smart Phone Agro-Advisory Services Acceptance Model on Climate Smart Natural Resource Management

Chen and Kotz (2000) stated that context is a Smart Phone computing environment determining how an application is used or the location where the application is used. The study considers 'Context' as exogenous variable influencing the endogenous variables viz., 'Perceived Usefulness' and 'Perceive Ease of Use.' This lead to the following hypotheses:

$\mathrm{H}_{1}$ : ' $\mathrm{C}$ ' has a positive and direct effect on 'PU'.

$\mathrm{H}_{2}$ : 'C' has a positive and direct effect on 'PEU'.

The 'Trust on Climate Smart Natural Resource Management' is defined as the belief in a farmer's competence to perform a specific task or expectancy that the AAS on Climate Smart Natural Resource Management of m4agriNEI can be relied upon. The role of smart phone services user trust with regard to the intention to adopt or use technology. User trust is crucial for the growth and success of smart phone services adoption, because engendering trust is not only time consuming but trust is also fragile and easily destroyed. Lack of trust is a barrier to the adoption of internet based services. Cho et al. (2007) indicated that the trust is much more complicated in smart phone commerce than in traditional commerce. The study considers 'Trust' as the exogenous variable influencing the endogenous variable - 'Intention to Accept.' These remarks lead to the following hypothesis.

H4: ' $\mathrm{T}$ ' positively influences 'IA'.

The 'Perceived Usefulness on Climate Smart Natural Resource Management' refers to farming-related productivity, performance and effectiveness on climate smart natural 
resource management. This construct has been found important in e-service context such as ecommerce, smart phone payment service, online banking and health information system (Mou \& Cohen 2014). Therefore, the following hypothesis is suggested.

H5: 'PU' positively affects 'IA'.

The 'Perceived Ease of Use on Climate Smart Natural Resource Management' refers to the degree to which a farmer judges that using the AAS of m4agriNEI on climate smart natural resource management will require little or no effort. Chau (1996) found that 'Perceived Ease of Use' is the most influential determinant of software acceptance. Igbaria et al. (1997) stated that 'Perceived Ease of Use' is a dominant factor explaining perceived usefulness as well as system use. 'Perceived Ease of Use' is more salient in the early stages of new technology use; once an individual is familiar with new technologies; the use of new technology becomes easy, which has a positive effect on 'Perceived Ease of Use' of the technology (Marchewka \& Liu 2007). This leads to the following Hypotheses.

H3: 'PEU' positively affects 'PU'.

H6: 'PEU' positively influences 'IA'.

The 'Intention to Accept on Climate Smart Natural Resource Management' is defined as personal willingness or likelihood of registered farmer to engage a particular behaviour on Climate Smart Natural Resource Management. Ajzen (1991) argues that Behavioural Intention reflects how much effort a person is willing to devote to performing a particular behaviour.

\section{Materials and Methods}

The present investigation was carried out in the three m4agriNEI project districts of Meghalaya viz., Ri-Bhoi, East Khasi Hills and West Jaintia Hills districts; and from which only the most agriculturally important Community and Rural Development Blocks (CRDBs) viz, Umsning (having 4427 registered farmers), Mylliem (having 1351 registered farmers) and Thadlaskein (having 895 registered farmers) were selected respectively, for selection of respondents. Taking into account, the total population of 10647 registered farmers under m4agriNEI in these three CRDBs (as per database on March, 2018), Confidence Interval of 5 and Confidence Level of 95 per cent, the sample size of 363 has been determined for the study. Since the investigation was focussed on developing a Smart Phone Agro-Advisory Services Acceptance Model, only frequent callers (registered farmers, who at least call 3 times a week to m4agriNEI lab for raising queries related to on Climate Smart Natural Resource Management in Agriculture and allied farming practices at College of P.G. Studies in Agricultural Sciences of CAU, Imphal at Umiam, Meghalaya) were selected as respondents for the study.

Due to the exploratory and confirmatory nature of the research problem, a survey research design was followed. Pretested structured interview schedule was administered for collection of socio-economic data of respondents. The software SPSS AMOS 21 was utilized in order to administer structural equation modelling approach in the study. 


\section{Results and Discussion}

The socio-economic characteristics of respondents in the study are discussed herewith by referring Table 1. A majority $(61.71 \%)$ of the respondents belonged to middle age group, followed by 33.88 and 4.41 per cent in the young and old age group. Educational level of the farmers is supposed to play a dynamic and vital role in accepting any innovation of ICT application in farming. It is evident from the data that more than fifty per cent $(52.34 \%)$ of the respondents had High School level of education which was followed by around one-third (32.78\%), one-tenth $(11.57 \%)$ and 3.31 per cent of farmers who had education up to higher secondary, graduation and above, and illiterate.

Table 1. Socio-economic and psychological characteristics of respondents

\begin{tabular}{|c|c|c|}
\hline Characteristics & Frequency & Percenta \\
\hline \multicolumn{3}{|l|}{ Age } \\
\hline $\begin{array}{l}\text { Young } \\
\text { years })\end{array} \quad(\leq 35$ & 123 & 33.88 \\
\hline $\begin{array}{l}\text { Middle }(36-50 \\
\text { years })\end{array}$ & 224 & 61.71 \\
\hline Old (> 50 years) & 16 & 4.41 \\
\hline \multicolumn{3}{|l|}{ Education } \\
\hline Illiterate & 12 & 3.31 \\
\hline High School & 190 & 52.34 \\
\hline Higher Secondary & 119 & 32.78 \\
\hline $\begin{array}{l}\text { Graduate } \\
\text { above }\end{array}$ & 42 & 11.57 \\
\hline
\end{tabular}

\section{Land Holding}

Characteristics Frequency Percentage

Small $(\leq 2$ Acre $)$
Medium $(2.1-4.0$
Acre $)$

Large (> 4.0)

86

Annual Income

Low ( $\leq$ Rupees 162

44.63

$67,000 /-)$

Medium (Rupees 168

46.28

67,001

2,33,000/-)

High (> Rupees 33

9.09

2,33,000/-)

Pro-Active Calls

to m4agriNEI

Lab Seeking AAS

Low (up to 11

49

13.50

calls/month)

Medium (between

130

35.81

12 to 17

calls/month)

High (above 18

184

50.69 calls/month)

It could be further perused from Table 1 , that more than fifty five per cent $(55.92 \%)$ followed by 23.69 per cent and 20.39 per cent of the respondents had Medium, Large and Small land holding for performing their agricultural and allied enterprises in the wake of climate change by on adapting and mitigating climate change in agriculture. It could be further revealed that higher percentage of 46.28 per cent, followed by 44.63 per cent and less percentage of 9.09 only percent of respondent's belonged to 
Medium, Low and High-Income group out of climate change affected agricultural and allied enterprises. Adoption of innovations by farmers tend to move ahead when there are more contacts with appropriate agents in right place and right time. By observing the data, with respect to Pro-Active Calls to m4agriNEI Lab Seeking AAS on Climate Smart Natural Resource Management, it could be unveiled that more than fifty percentage $(50.69 \%)$ of respondent were high in call rates-calling more than eighteen (18) calls a month. Considerable percentage of about thirty five percent $(35.81 \%)$ followed by less percentage of about thirteen percent $(13.50 \%)$ belonged to the categories of Medium and Low Pro-active calls to m4agriNEI Lab for seeking AAS on Climate Smart Natural Resource Management.

\section{Theory testing and findings}

Observed variables in the study are represented by 27 questions that attempt to capture the five latent variables. Scale reliability is measured by Cronbach's alpha. Table 2 shows the Cronbach's alpha reliabilities for each theoretical constructs and number of items in each scale. As it can be referred from Table 2, all Cronbach's alpha values for the variables representing the studied concepts are higher than 0.9. These values are higher than the critical values of Cronbach's alpha determined by Nunnally (1978). The scales measuring the latent variables are considered to be credible, since alpha values associated are higher than 0.9. All corrected item and total correlation values are greater than 0.2 , so none of the questions were deleted.

Table 2. Cronbach's alpha Values of scales

\begin{tabular}{lcc}
\hline Scale & $\begin{array}{c}\text { Number of } \\
\text { questions }\end{array}$ & $\begin{array}{c}\text { Cronbach's } \\
\text { alpha }\end{array}$ \\
\hline $\mathrm{C}$ & 7 & 0.916 \\
$\mathrm{~T}$ & 7 & 0.934 \\
$\mathrm{PU}$ & 5 & 0.910 \\
$\mathrm{PEU}$ & 5 & 0.924 \\
$\mathrm{IA}$ & 3 & 0.923
\end{tabular}

In order to determine how well the questions, which are the latent variables indicators, can represent the whole model, the Confirmatory Factor Analysis (CFA) is employed in the study. It compares two different structures: a theoretical one and one created via data for testing hypotheses between the latent and model variables (Bryman \& Cramer 2005). To refine the measures, we conducted a confirmatory analysis to determine the validity and reliability of our measures and results are demonstrated in Table 3.

Table 3. Standardized (Std.) Loadings and t-values for subscale's confirmatory factor analysis

\begin{tabular}{ccccc}
\hline Factors & Observed Variables & Std. Loadings & Error Variance & t-values \\
\hline C & C1 & 1.01 & 0.66 & 15.64 \\
& C2 & 0.79 & 0.91 & 16.11
\end{tabular}




\begin{tabular}{|c|c|c|c|c|}
\hline 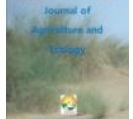 & \multicolumn{3}{|c|}{$\begin{array}{l}\text { Journal of Agriculture and Ecology, 2020, Vol. 9, 67-77 } \\
\qquad \underline{\text { http://saaer.org.in }}\end{array}$} & \\
\hline \multirow{11}{*}{$\mathrm{T}$} & C3 & 0.73 & 0.87 & 14.48 \\
\hline & $\mathrm{C} 4$ & 0.96 & 0.73 & 17.22 \\
\hline & C5 & 0.88 & 0.82 & 16.29 \\
\hline & C6 & 0.91 & 0.71 & 18.81 \\
\hline & $\mathrm{C} 7$ & 1.0 & 0.62 & 17.23 \\
\hline & $\mathrm{T} 1$ & 2.08 & 0.80 & 15.29 \\
\hline & $\mathrm{T} 2$ & 1.86 & 0.98 & 16.28 \\
\hline & $\mathrm{T} 3$ & 0.14 & 1.27 & 18.29 \\
\hline & $\mathrm{T} 4$ & 0.53 & 1.38 & 16.29 \\
\hline & $\mathrm{T} 5$ & 0.75 & 1.38 & 16.84 \\
\hline & T6 & 1.95 & 1.18 & 15.28 \\
\hline \multirow{4}{*}{$\mathrm{PU}$} & $\mathrm{T} 7$ & 1.00 & 1.21 & 18.02 \\
\hline & PU1 & 1.00 & 0.55 & 16.52 \\
\hline & PU2 & 1.04 & 0.42 & 15.28 \\
\hline & PU3 & 1.02 & 0.45 & 17.11 \\
\hline \multirow{5}{*}{ PEU } & PU4 & 1.00 & 0.60 & 16.24 \\
\hline & PU5 & 1.02 & 0.65 & 17.22 \\
\hline & PeU1 & 1.00 & 0.56 & 12.24 \\
\hline & PeU2 & 0.84 & 0.63 & 11.29 \\
\hline & PeU3 & 0.96 & 0.42 & 14.54 \\
\hline \multirow{5}{*}{ IA } & PeU4 & 0.95 & 0.54 & 14.99 \\
\hline & Peu5 & 0.92 & 0.51 & 15.28 \\
\hline & It 1 & 1.00 & 4.59 & 16.99 \\
\hline & It 2 & 0.77 & 0.39 & 15.28 \\
\hline & It3 & 0.83 & 2.13 & 16.24 \\
\hline
\end{tabular}

Perusal of Table 3 and Figure 2 could to 1.04 with error variance between 15.28 to reveal that the standardised factor loadings of ' $C$ ' range from 0.73 to 1.01 , with error variance between 0.62 and 0.91 . Similarly, the standardised factor loading of ' $\mathrm{T}$ ' ranges from 0.14 to 2.08 with error variance between 0.80 to 1.38. For the construct - 'PU', the 17.22. The assortment of 0.84 to 1.00 is the range of standard factor loading for 'PEU' with the error variance between 11.29 to 15.28. The standard factor loading for ' $I A$ ' is between 0.39 to 4.59 with error variance between 15.28 and 16.99 .

standardised factor loading ranges from 1.00 


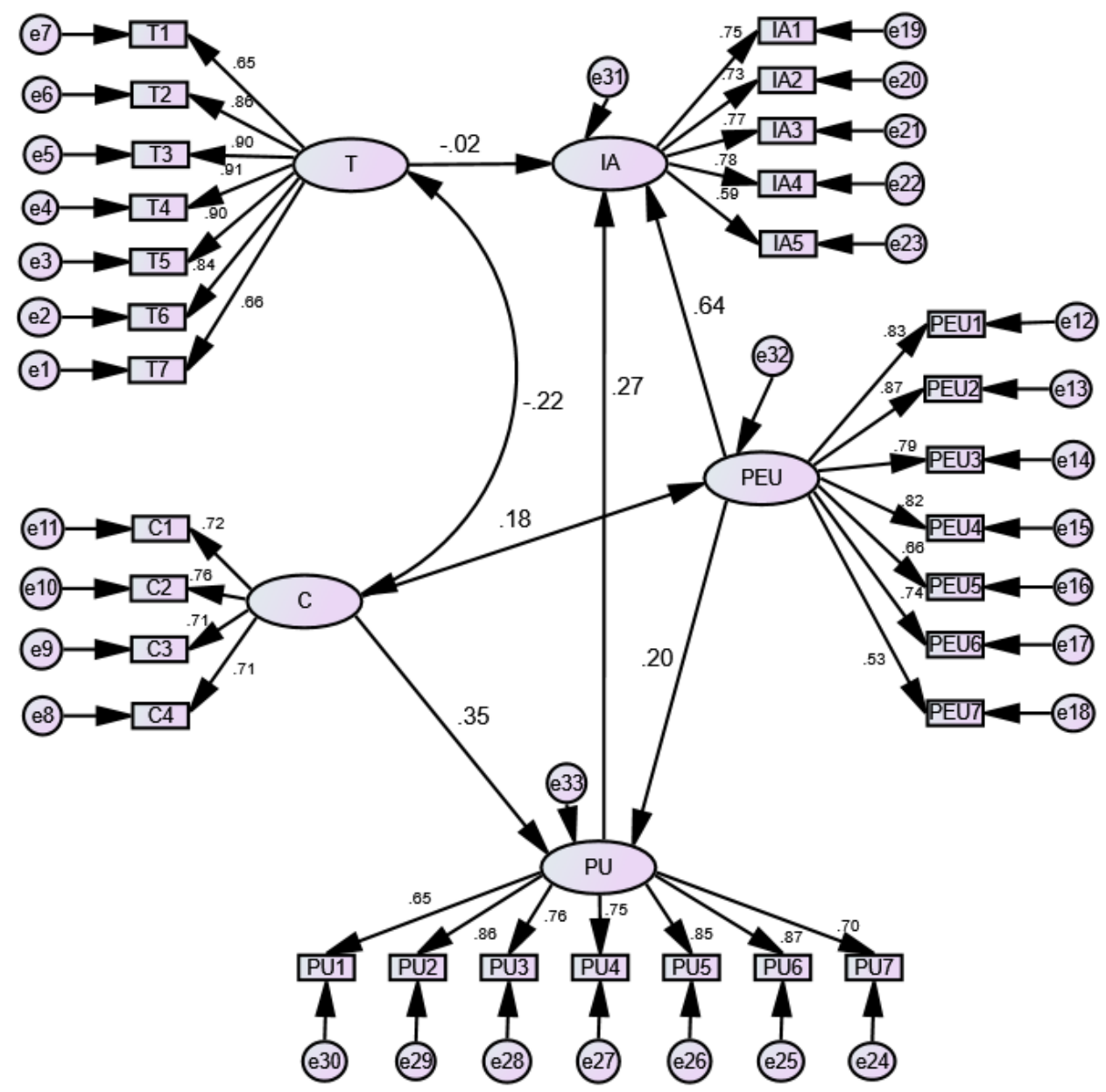

Figure 2. Confirmatory factor analysis for smart phone agro-advisory services acceptance model on climate smart natural resource management

Therefore, context, trust, perceived usefulness, perceived ease of use, and intention to accept are five concrete factors which can be proposed for a model to be confirmed.

\section{Structural model-test of hypotheses}

The structural modelling was performed to test whether the observed data fits a theoretical model through hypothesis testing. The fit indices for measurement model and structural model are presented in Table 4. The results given in Table 4 show that the specified model had Normed Chi-square value $=0.294$, GFI $=1.11, \mathrm{SRMR}=0.91$ and RMSEA $=0.924$, indicating adequate model fit.

Table 4. Goodness-of-Fit indices of measurement and structural model

\begin{tabular}{lcc}
\hline Fit statistics & $\begin{array}{c}\text { Decision } \\
\text { criteria } \\
\text { (source) }\end{array}$ & Result \\
\hline$\chi^{2} / d f$ & $<3.00$ (Hair et & 0.294 \\
& al. 1998) &
\end{tabular}




\begin{tabular}{lll}
\hline Fit statistics & $\begin{array}{c}\text { Decision } \\
\text { criteria } \\
\text { (source) }\end{array}$ & Result \\
\end{tabular}

\begin{tabular}{ccc}
\hline GFI & $>0.9$ (Hair et al. & 1.11 \\
$1998)$ &
\end{tabular}

SRMR $<0.08$ (Hu \& Bentler, 1999)

RMSEA $<$ 0.05). Again, ' $\mathrm{C}$ ' had a strong direct positive relationship with 'PEU' $\left(\mathrm{H}_{2}: \gamma=0.94\right.$, $p<0.01)$. The 'PEU' had direct and positive relationship with 'PU' $\left(\mathrm{H}_{3}: \gamma=0.21, p<\right.$ 0.05). The variable ' $\mathrm{T}$ ' had high direct positive impetus on 'IA' $\left(\mathrm{H}_{4}: \gamma=3.12, p<\right.$ $0.01)$. Similar to above relationship, the 'PU' had positive relationship with 'IA' $\left(\mathrm{H}_{5}: \gamma=\right.$ $0.18, p<0.05)$, and 'PEU' had positive relationship with 'IA' $\left(\mathrm{H}_{6}: \gamma=0.34, p<0.05\right)$.

(Tabachnik \&

Fidell, 2007)

Given a satisfactory measurement of the model's fit to the observed data, the path coefficients of the structural model were assessed. The Hypotheses $-\mathrm{H}_{1}$ to $\mathrm{H}_{6}$ were tested by assessing the significance of the path coefficients, which indicate the strength of a relationship between variables. The results of the analysis as depicted in Table 5 show that all proposed hypotheses $\left(\mathrm{H}_{1}\right.$ to $\left.\mathrm{H}_{6}\right)$ are accepted.

Table 5. Path co-efficient and t-values

\begin{tabular}{lccc}
\hline $\begin{array}{l}\text { Fit } \\
\text { statistics }\end{array}$ & Path & $\begin{array}{c}\text { Path } \\
\text { coefficient }\end{array}$ & Result \\
\hline $\mathrm{H}_{1}$ & $\mathrm{C} \rightarrow \mathrm{PU}$ & $0.28^{*}$ & Supported \\
$\mathrm{H}_{2}$ & $\mathrm{C} \rightarrow$ & $0.94^{* *}$ & - do - \\
& $\mathrm{PEU}$ & & \\
$\mathrm{H}_{3}$ & $\mathrm{PEU} \rightarrow$ & $0.21^{*}$ & - do - \\
& $\mathrm{PU}$ & & \\
$\mathrm{H}_{4}$ & $\mathrm{~T} \rightarrow \mathrm{IA}$ & $3.12^{* *}$ & - do - \\
$\mathrm{H}_{5}$ & $\mathrm{PU} \rightarrow \mathrm{IA}$ & $0.18^{*}$ & - do - \\
$\mathrm{H}_{6}$ & $\mathrm{PEU} \rightarrow$ & $0.34^{*}$ & - do - \\
& IA & & \\
\hline
\end{tabular}

As hypothesized, the ' $\mathrm{C}$ ' was directly and positively related to 'PU' $\left(\mathrm{H}_{1}: \gamma=0.28, p\right.$

\section{Conclusion}

Advancement in smart phone enabled services and exceptional increases in the speed (4G internet connectivity in rural areas), reliability, scope, and accuracy of communication and information exchange through text, voice, and video applications have created new opportunities for farmers to connect with their partners (peer farmers, researchers, extension and advisory service providers, agribusiness, or others important to farmers' lives and enterprises) in ways that enhance their productivity and incomes through adaptation and mitigation of climate change by adopting and assimilating recommended climate smart natural resource management. Smart phone based information delivery holds great promise and it is in use as a major channel for agricultural advisory services. The 'Smart Phone Agro-Advisory Services Acceptance Model' of m4agriNEI is a successful model on empowering the tribal farmer of Meghalaya by providing right information in right time through a smart phone based agro-advisory system on climate smart natural resource management in agriculture and allied enterprises by tribal farmers of the hill state Meghalaya. It is confirmed by the empirical study that has been 
rigorously performed in the study with strict psychometric and statistical tools.

\section{References}

Ajzen I. 1991. The theory of planned behavior. Organizational Behaviour and Human Decision Processes, 50: 179211.

Bryman A \& Cramer D. 2005. Quantitative data analysis with SPSS 12 and 13. London: Routledge.

Chau P. 1996. An empirical investigation on factors affecting the acceptance of CASE by systems developers. Information \& Management, 30: 269280.

Chen G \& Kotz D. 2000. A survey of contextaware smart phone computing research (Dartmouth Computer Science Technical Report).

Cho D, Kwon H \& Lee H. 2007. Analysis of trust in internet and Smart Phone commerce adoption. In The $40^{\text {th }}$ Hawaii international conference on system science.

Gao S, Krogstie J \& Gransæther P. 2008. Smart Phone services acceptance model. In International conference on convergence and hybrid information technology (pp. 446e453) (Daejeon, Korea).

Gao S, Krogstie J \& Siau K. 2011. Developing an instrument to measure the adoption of Smart Phone services. Smart Phone Information Systems, 7: 45-67.

Government of Meghalaya (GoM). 2016. Meghalaya Agriculture Profile, Department of Agriculture, Government of Meghalaya.

Hair J, Black W, Babin B \& Anderson R. 2010. Multivariate data analysis: A global perspective (7th ed.). Upper Saddle River, NJ: Pearson Education.

Hu L \& Bentler P. 1999. Cutoff criteria for fit indexes in covariance structure analysis: Conventional criteria versus new alternatives. Structural Equation Modelling: A Multidisciplinary Journal, 6(1): 1-55.

Mallat N, Rossi M, Tuunainen V \& Oorni A. 2009. The impact of use context on Smart Phone services acceptance: The case of Smart Phone ticketing. Information \& Management, 46(3): 190195.

Marchewka J \& Liu C. 2007. An application of the UTAUT model for understanding student perceptions using course management software. Communications of the IIMA, 7(2): 93-104.

Mou J \& Cohen J.(2014. A longitudinal study of trust and perceived usefulness in consumer acceptance of an e-service: The case of online health services. Pacific Asia Conference on Information Systems (PACIS).

Nunnally J. 1978. Psychometric Theory. McGraw-Hill: New York.

Sarker S \& Wells D. 2003. Understanding Smart Phone handheld device use and adoption. Communications of the ACM, 46(12): 35-40.

Schierz P, Schilke O \& Wirtz B. 2010. Understanding consumer acceptance of Smart Phone payment services: An empirical analysis. Electronic Commerce.

Tabachnick B \& Linda S. 2007. Using multivariate statistics. Boston: Pearson/Allyn \& Bacon. 